\title{
Tula hantavirus infection in a hospitalised patient, France, June 2015
}

JM Reynes ${ }^{1}$, D Carli ${ }^{1}$, N Boukezia ${ }^{2}$, M Debruyne ${ }^{3}$, S Herti 4

1. Centre National de Référence des Hantavirus, Unité de Biologie des Infections Virales Emergentes, Institut Pasteur, Centre International de Recherche en Infectiologie, Lyon, France

2. Laboratoire, Centre Hospitalier de Coulommiers, Coulommiers, France

3. Laboratoire Cerba, Cergy Pontoise, France

4. Service de Médecine Interne, Centre Hospitalier de Coulommiers, Coulommiers France

Correspondence: Jean-Marc Reynes (jean-marc.reynes@pasteur.fr)

Citation style for this article:

Reynes J, Carli D, Boukezia N, Debruyne M, Herti S. Tula hantavirus infection in a hospitalised patient, France, June 2015. Euro Surveill. 2015;20(50):pii=30095. DOI: http://dx.doi.org/10.2807/1560-7917.ES.2015.20.50.30095

Article submitted on 30 November 2015 / accepted on 17 December 2015 / published on 17 December 2015

We report an infection with Tula virus in June 2015, leading to hospitalisation, in a patient living approximately $60 \mathrm{~km}$ east of Paris with no previous remarkable medical history. Clinical symptoms were limited to a fever syndrome with severe headache. The main laboratory findings included thrombocytopenia and elevated transaminase levels. Based on S (small) gene sequence analysis, the strain affecting the patient was closely related to strains detected in Central Europe, especially to a south-east German strain.

\section{Case report}

In June 2015, man in his mid-thirties presented to hospital, three days after the appearance of symptoms (day 3) including sudden fever onset, diffuse pain including back pain, headache and weakness. His previous lifetime medical history was unremarkable with no reported alcohol dependence. His body temperature was $39.6^{\circ} \mathrm{C}$ and he reported a severe headache. Physical examination did not reveal any further abnormalities. Blood pressure, and heart and respiratory rate measures were normal. Blood test results however revealed thrombocytopenia, leucopenia, and elevated transaminase and C-reactive protein values (Table).

Results of a chest X-ray and magnetic resonance imaging of the brain found no abnormality. However, abdominal ultrasound demonstrated moderate enlargement of the liver and spleen (lengths $144 \mathrm{~mm}$ and $128 \mathrm{~mm}$ respectively). The patient was hospitalised and symptomatic treatment was carried out. Serological investigations were requested, to test for cytomegalovirus, Epstein-Barr virus, hantavirus, viral hepatitis, human immunodeficiency virus and parvovirus B19 infection. A microscopic haematuria was observed on day 6 (20,000 red blood cells $/ \mathrm{mL}$ ) but renal function remained unaltered (Table). Symptoms disappeared during the hospitalisation. Blood parameters returned to normal, in particular liver parameters and platelet count (Table). The patient was discharged on day 16.

\section{Aetiological investigation}

Serological tests were negative, except for tests for the detection of IgM and IgG against hantaviruses (Hantavirus Pool 1 'Eurasia' IgG and Hantavirus Pool 1 'Eurasia' IgM; Euroimmun), including a mixture of purified recombinant nucleocapsid proteins from Hantaan, Dobrava, and Puumala virus (PUUV). These tests were positive on a serum sample collected on day 4 (ratios 1.8 and 4.7 for IgM and IgG respectively, both above the cut-off value of 1.1). As usual in France for surveillance purposes, the sample with positive results was then transferred to the National Reference Centre for Hantavirus. The acute hantavirus infection was serologically confirmed using PUUV native antigen in enzyme-linked immunosorbent assays and immunofluorescence assay, the results being negative using Seoul virus (SEOV) native antigen (both antigens are routinely used). The serum sample was subsequently tested for the presence of hantavirus RNA. The assay was negative using a real-time reverse transcriptionpolymerase chain reaction (RT-PCR) targeting part of the small (S) genome segment of PUUV, but positive using a pan-hantavirus nested RT-PCR targeting part of the large ( $L$ ) segment, and a Arvicolinae-borne hantavirus nested RT-PCR targeting part of the S segment, PUUV being used as positive control [1-3].

Amplicons were sequenced and an analysis by basic local alignment search tool indicated that both sequences were very similar to those of Tula virus (TULV) strains, especially to that of the south-east German rodent strain GER/152/Arv (GenBank accession numbers: HQ728459 and HQ697350). Compared to this strain, the patient strain had $89.5 \%$ and $90.2 \%$ respective nucleotide (nt) sequence identities to the partial 


\section{FIGURE}

Phylogenetic analysis of the Tula hantavirus strain found in an infected patient in France, June 2015

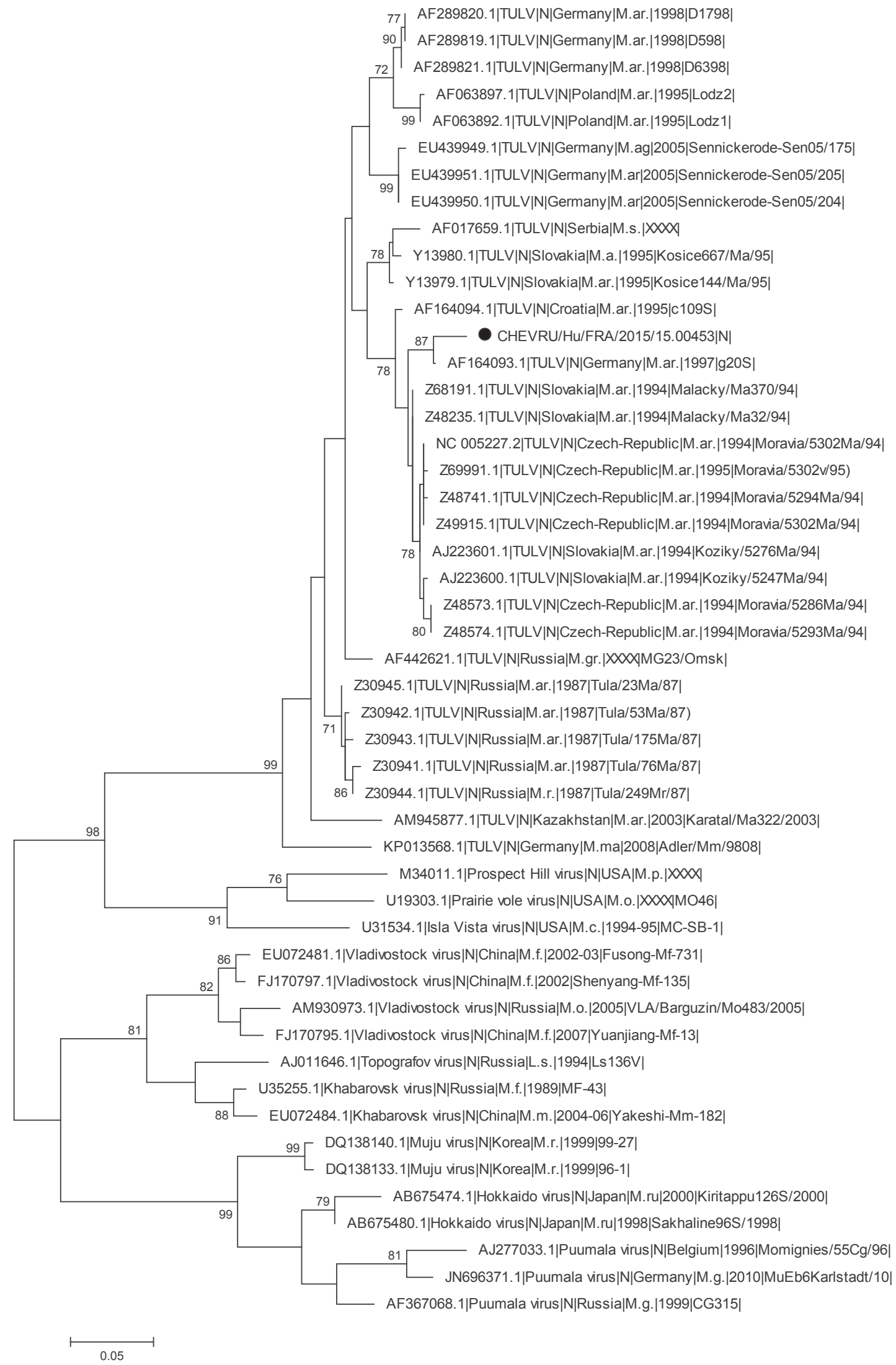

The phylogenetic analysis is based on the entire nucleotide (nt) coding sequence of the small (S) genome segment. Sequences from strains of Tula virus and other Arvicolinae-borne hantaviruses are included in the phylogenetic tree and the French Tula virus strain CHEVRU/Hu/ FRA/2015/15.00453 retrieved in this study is indicated by a full circle. Bootstrap percentages $\geq 70 \%$, from 500 re-samplings are indicated at each node. The scale bar indicates nt substitutions per site. Sequences were aligned by Muscle, and the tree was constructed using molecular evolutionary genetics analysis (MEGA) version 5.1 with the maximum likelihood method. According to the best fit substitution model proposed, analyses were performed applying the Tamura Nei model using a gamma distribution (+ G) with five rate categories. 
TABLE

Haematological and biochemical findings of a Tula hantavirus-infected patient, France, June 2015

\begin{tabular}{|l|c|c|c|c|c|c|c|c|}
\hline \multirow{2}{*}{ Parameters measured on blood specimen } & \multirow{2}{*}{ Unit } & \multirow{2}{*}{ Norm } & \multicolumn{5}{|c|}{ Day of sampling } \\
\cline { 5 - 10 } & & & Day 3 & Day 6 & Day 9 & Day 11 & Day 16 & Day 25 \\
\hline White cells & $10^{9} / \mathrm{L}$ & $4-10$ & 2.1 & 6.4 & 4.3 & 5.4 & 4.5 & 4.6 \\
\hline Platelets & $10^{9} / \mathrm{L}$ & $150-450$ & 100 & 31 & 88 & 177 & 300 & 254 \\
\hline Haemoglobin & $\mathrm{g} / \mathrm{dL}$ & $13-17$ & 15.7 & 16.5 & 14.0 & 14.9 & 14,5 & 13.8 \\
\hline C-reactive protein & $\mathrm{mg} / \mathrm{L}$ & $<5$ & 17 & 19 & 4 & ND & ND & ND \\
\hline Aspartate aminotransferase & $\mathrm{IU} / \mathrm{L}$ & $10-50$ & 114 & 174 & 106 & 188 & 55 & 43 \\
\hline Alanine transaminase & $\mathrm{IU} / \mathrm{L}$ & $10-50$ & 163 & 232 & 223 & 322 & 162 & 78 \\
\hline Gamma-glutamyltransferase & $\mathrm{IU} / \mathrm{L}$ & $8-61$ & 112 & 273 & 228 & 236 & 153 & 121 \\
\hline Prothrombin ratio & $\%$ & $70-100$ & 88 & 97 & ND & ND & ND & ND \\
\hline Creatinine & $\mu \mathrm{mol} / \mathrm{L}$ & $62-106$ & 93 & 72 & 81 & ND & 80 & 80 \\
\hline
\end{tabular}

IU: international unit; ND: not done.

a The sampling day refers to the number of days after symptom onset.

$L(n=347 n t)$ and $S$ segments $(n=307 n t)$. This corresponded, at the amino acid (aa) level, to $99.1 \%(n=115)$ and $100 \% \quad(n=102)$ aa identity (partial L sequence deposited in GenBank database under accession number: KU297981).

The complete S coding DNA sequence (CDS) (GenBank accession number: KT946591) was recovered via three nested RT-PCRs using primers reported elsewhere [4], producing three overlapping amplicons. The aa sequence $(n=429$ aa) was similar to those of TULV strains reported in GenBank (divergence 0.2 to $4.9 \%$ ), and presented highest similarity at the nt and aa levels with the sequence of the rodent Bavarian German strain g20 (GenBank accession number: AF164093). Using molecular evolutionary genetics analysis (MEGA) version 5.1 [5], a phylogenetic analysis based on the $\mathrm{S}$ segment coding domain sequence confirmed that the strain - named CHEVRU/Hu/FRA/2015/15.00453 belonged to the TULV species, and was most closely related to the g20 south-east German strain (Figure).

Sequence comparison was also performed with a reduction of the S CDS dataset to $297 \mathrm{nt}$ (positions $865-1,161$ according to the numbering of our sequence) in order to include the only two TULV partial sequences reported from France and detected in Microtus arvalis [6]. Divergence at the aa level was $4.0 \%$ with these two sequences (compared to only $1.0 \%$ with the g20 sequence). The phylogenetic analysis was also performed with this dataset. The French human and animal strains were not closely related but the statistical support was low (data not shown).

\section{Background}

Five zoonotic hantaviruses have been described in Europe: Dobrava-Belgrade (DOBV), PUUV, Saaremaa, SEOV and TULV. Among these, PUUV and DOBV are responsible for most human infections, causing mild to severe haemorrhagic fever with renal syndrome [7-9]. The pathogenic potential of TULV in humans is not well known. Although, this virus was found in rodent samples from numerous European countries (including France) after its first identification in 1994 from Microtus spp. rodents sampled in 1987 in Tula (Russia), it has only been reported once in humans, from an immunocompromised patient [7-11].

\section{Epidemiological investigation}

The investigation was limited to an interview of the patient. The patient lived in a small rural village, surrounded by flat open fields of corn, wheat and sugar beet, in the west part of the Seine-et-Marne department (ca $60 \mathrm{~km}$ east of Paris). He was working as an aircraft engine technician. During the six weeks before disease onset, he had often thrown away, barehanded, voles (unidentified species) taken back home by his pet cat. He reported during that period one bite by a live vole. Other potential sources of contamination were not reported.

\section{Discussion}

TULV infection in humans without symptoms has been serologically documented [12]. However, evidence of disease in patients is rare with only three such cases being reported (see [7,10] for review). Among these, one, which occurred after a wild rodent bite remained controversial, as clinical symptoms were more compatible with rat-bite fever and late seroconversion suggested that although TULV infection may have occurred, it was perhaps not responsible for the symptoms [13]. From the three reported symptomatic cases, TULV was detected in only one, which was immunocompromised. The molecular evidence of TULV infection in our patient confirms the pathogenic potential of TULV, as this lead to hospitalisation. Furthermore, we mainly observed a fever syndrome with an alteration of the liver function, whereas the two previous non-controversial cases reported, both exhibited a renal and pulmonary syndrome $[10,14]$. Reported cases are too rare to draw any conclusions about the main tropism of TULV. 
Routine hantavirus diagnosis in France is based on commercial serological assays that do not allow discrimination between different hantavirus infections, and consequently diagnosed infections are mostly attributed to PUUV, the main prevalent hantavirus in Europe. Using serological and molecular diagnostic assays as confirmation tests, we recently confirmed virologically for the first time in Europe a human SEOV infection [15]. The diagnostic of this TULV and SEOV infection indicate that molecular diagnostics of hantavirus should be promoted in order to discriminate between hantaviruses involved in human diseases.

\section{Acknowledgements}

The Centre National de Référence des Hantavirus receives financial support from the Institut de Veille Sanitaire (InVS) (http://www.invs.fr/). We also thank Philip Lawrence for his contribution as native English speaker.

\section{Conflict of interest}

None declared.

\section{Authors' contributions}

Samir Herti and Nourredine Boukezia took care of the patient. Monique Debruyne performed hantavirus serological analysis. Damien Carli and Jean-Marc Reynes performed the molecular detection and analysis of the Tula virus strain. Jean-Marc Reynes and Samir Herti wrote the manuscript. All co-authors reviewed the manuscript.

\section{References}

1. Kramski M, Meisel H, Klempa B, Krüger DH, Pauli G, Nitsche A. Detection and typing of human pathogenic hantaviruses by real-time reverse transcription-PCR and pyrosequencing. Clin Chem. 2007;53(11):1899-905. DOI: 10.1373/ clinchem.2007.093245 PMID: 17717126

2. Bowen MD, Gelbmann W, Ksiazek TG, Nichol ST, Nowotny N. Puumala virus and two genetic variants of Tula virus are present in Austrian rodents.J Med Virol. 1997;53(2):17481. DOI: 10.1002/(SICI)1096-9071(199710)53:2<174::AID JMV11>3.0.CO;2-J PMID: 9334930

3. Klempa B, Fichet-Calvet E, Lecompte E, Auste B, Aniskin $\mathrm{V}$, Meisel $\mathrm{H}$, et al. Hantavirus in African wood mouse, Guinea. Emerg Infect Dis. 2006;12(5):838-40. DOI: 10.3201/ eid1205.051487 PMID: 16704849

4. Tkachenko EA, Witkowski PT, Radosa L, Dzagurova TK, Okulova NM, Yunicheva YV, et al. Adler hantavirus, a new genetic variant of Tula virus identified in Major's pine voles (Microtus majori) sampled in southern European Russia. Infect Genet Evol. 2015;29:156-63. DOI: 10.1016/j.meegid.2014.11.018 PMID: 25433134

5. Tamura K, Peterson D, Peterson N, Stecher G, Nei M, Kumar S. MEGA5: molecular evolutionary genetics analysis using maximum likelihood, evolutionary distance, and maximum parsimony methods. Mol Biol Evol. 2011;28(10):2731-9. DOI: 10.1093/molbev/msr121 PMID: 21546353

6. Plyusnina A, Deter J, Charbonnel N, Cosson JF, Plyusnin A. Puumala and Tula hantaviruses in France.Virus Res. 2007;129(1):58-63. DOI: 10.1016/j.virusres.2007.04.023 PMID: 17532080

7. Olsson GE, Leirs H, Henttonen $\mathrm{H}$. Hantaviruses and their hosts in Europe: reservoirs here and there, but not everywhere?Vector Borne Zoonotic Dis. 2010;10(6):549-61. DOI: $10.1089 / v b z .2009 .0138$ PMID: 20795916

8. Vaheri A, Henttonen H, Voutilainen L, Mustonen J, Sironen T, Vapalahti O. Hantavirus infections in Europe and their impact on public health. Rev Med Virol. 2013;23(1):35-49. DOI: 10.1002/ rmv.1722 PMID: 22761056
9. Klempa B, Avsic-Zupanc T, Clement J, Dzagurova TK, Henttonen $\mathrm{H}$, Heyman $\mathrm{P}$, et al. Complex evolution and epidemiology of Dobrava-Belgrade hantavirus: definition of genotypes and their characteristics. Arch Virol. 2013;158(3):521-9. DOI: 10.1007/s00705-012-1514-5 PMID: 23090188

10. Zelená H, Mrázek J, Kuhn T. Tula hantavirus infection in immunocompromised host, Czech Republic.Emerg Infect Dis. 2013;19(11):1873-5. DOI: 10.3201/eid1911.130421 PMID: 24209605

11. Plyusnin A, Vapalahti $O$, Lankinen $H$, Lehväslaiho H, Apekina $\mathrm{N}$, Myasnikov Y, et al. Tula virus: a newly detected hantavirus carried by European common voles. J Virol. 1994;68(12):78339.PMID: 7966573

12. Mertens M, Hofmann J, Petraityte-Burneikiene R, Ziller M, Sasnauskas K, Friedrich R, et al. Seroprevalence study in forestry workers of a non-endemic region in eastern Germany reveals infections by Tula and Dobrava-Belgrade hantaviruses. Med Microbiol Immunol (Berl). 2011;200(4):263-8. DOI: 10.1007/s00430-011-0203-4 PMID: 21611907

13. Clement J, Frans J, Van Ranst M. Human Tula virus infection or rat-bite fever?Eur J Clin Microbiol Infect Dis. 2003;22(5):332-3, author reply 334-5.DOI: $10.1128 / J C M .41 .10 .4894-4897.2003$ PMID: 12736795

14. Klempa B, Meisel H, Räth S, Bartel J, Ulrich R, Krüger DH. Occurrence of renal and pulmonary syndrome in a region of northeast Germany where Tula hantavirus circulates.J Clin Microbiol. 2003;41(10):4894-7. DOI: 10.1128/JCM.41.10.48944897.2003 PMID: 14532254

15. Macé G, Feyeux C, Mollard N, Chantegret C, Audia S, Rebibou JM, et al. Severe Seoul hantavirus infection in a pregnant woman, France, October 2012. Euro Surveill. 2013;18(17):20464.PMID: 23647626 